\title{
Suggestions for Creating a Welcoming Nursing Community: Ubuntu, Cultural Diplomacy, and Mentoring
}

\author{
School of Nursing Sciences \\ Northwest University \\ Martha M. Libster, PhD, RN \\ College of Nursing \\ East Carolina University
}

Fhumulani Mavis Mulaudzi, PhD, RN

Salaminah Phiri, M.Cur.

University of Pretoria

\begin{abstract}
Although there is historical evidence that nursing has been a profession that nurtures and affirms young nurses, some have observed recently that senior nurses "eat their young" and that there is a lack of student nurse socialization, creating poor role identification. Some young nurses are leaving the profession. This paper suggests that senior nurses consider the implementation of the African community-building philosophy of ubuntu to guide their interactions with young nurses. Cultural diplomacy and mentoring are discussed as means of implementing ubuntu philosophy in the creation of a welcoming nursing community.
\end{abstract}

Key Words: Ubuntu, cultural diplomacy, mentoring, nursing philosophy, socialization.

\section{Introduction}

Some of the most important worldwide rituals surround the preparation for the birth of a child. It is common for parents, siblings, and family members to hold joyful celebrations where gifts are given to the expectant parents. The gifts of love and support for the new child include material items, such as diapers and baby toys; they also include gifts that will nourish the new baby spiritually and emotionally, such as sound advice from grandparents and friends. The welcoming family and community provide the scaffold for the healthy development of the newborn. Like the infant, people of all ages need to be welcomed whenever they embark upon a new phase in their lives. When a person decides to become a nurse and they begin the education and socialization process, they encounter a new culture: professional nursing. Will the student nurse be welcomed by the "parents" and elders of the nursing community as they are born to nurse others?

The socialization process in nursing has been described as culture acquisition and an "active process that requires motivation and self-direction in the mentoring process" (Gray \& Smith, 1999, p. 640). More recently, some have made the observation that young nurses are being "eaten" rather than motivated and welcomed as they enter their professional community. This has been referred to as "toxic mentoring" (Webb \& Shakespeare, 2008, p. 564). Unfortunately, nurse mentors who become toxic are unable to form constructive relationships with mentees because they suffer from such issues as "burnout" (Webb \& Shakespeare). The literature on incivility, another example of the manifestation of unwelcoming behavior toward young nurses, indicates that the problem is also occurring in nursing education programs and is becoming more common (Clark \& Carnosso, 2008; Clark \&
Springer, 2007; Rieck \& Crouch, 2007).

Researching the roots of socialization of young nurses can be helpful in examining the problems in nursing culture. Historical inquiry may be used to identify if nurses have always eaten their young as part of their professional culture or if this phenomenon is new, perhaps as a result of greater social changes. This kind of evidence is certainly discoverable. There is some support that senior nurses have not always eaten their young. The history of the Daughters of Charity in Europe and the United States, for example, reveals that new nurses were greatly supported by their expert and experienced sister-nurse companions (Libster \& McNeil, in press). That tradition of community and sisterly support for new nurses, which continues to this day, has been preserved for almost 400 years in the instructional writings and correspondence to the sister-nurses by Louise de Marillac, who founded the Daughters of Charity in France with Vincent de Paul in 1633 (Sullivan, 1991).

This paper, however, will not be an analysis of the problem; rather it moves directly into some suggestions for solutions to the problem of how to create a welcoming community and professional culture that nourishes and affirms new nurses. These solutions include three foci as the foundation for community-building, which we assert is the first step to solving the problem of socializing young nurses. The three foci 
are philosophy, culture, and relationship. This paper specifically suggests the African philosophy of ubuntu, which emphasizes the principles of collectivism, solidarity, cohesiveness, and participatory leadership, to prepare senior nurses to better nurture and affirm young nurses. The paper also suggests that cultural diplomacy and mentoring be used to implement ubuntu philosophy in the creation of a welcoming nursing community for young nurses.

\section{Ubuntu Philosophy}

Philosophies usually provide guidance on how the world and society can be viewed. The behavior of an individual is determined by social systems. In African society, the upbringing of a child is rooted in a philosophy known as ubuntu. The term is derived from an African idiom that states, "Umuntu ngumuntu nga bantu." Literally translated it means, "I am because you are and you are because I am - A person is a person through other persons" (Mapadimeng, 2007, p. 257). Ubuntu is the Nguni language (South African language). The term is known in different parts of South Africa as well as other African countries. For example, in Tanzania, ubuntu is "ujamaa" and in Zimbabwe it is "huhnu" (Broodryk, 2002).

In his description of ubuntu, one of the well-known traditional healers in South Africa, Dr. Credo Mutwa said:

Ubuntu is not easy to describe. It is both a philosophy and a way of action. It is a distinctive African cosmological system of teaching each individual to appreciate and enjoy their life while caring, sharing, and respecting others. Ubuntu belongs to no one tribe or no one religion or teaching. It transcends all attempts to restrict it and place it in a category. It is simply a way of living and being that allows our basic goodness to come forth. (as cited in Kehoe, 2007, p.1)

His arguments are echoed by many authors who maintain that ubuntu is about humanness (Broodryk, 2002; Kamwangamalu
\& Nkonko,1999; Mulaudzi, 2007).

Kamwangamalu and Nkonko translated the term ubuntu to mean personhood or humanness. Because of this, ubuntu values are congruent with the virtue ethics of caring embraced in nursing. Virtue ethics instil responsibility. Both ubuntu and virtue ethics enable an individual to embrace community or "we" thinking in addition to individual or "I" thinking. Virtue ethics emphasize personal traits, such as respect, caring, compassion, kindness, warmth, understanding, sharing, humanness, reaching out, wisdom, and neighborliness (Mulaudzi). Similarly, the philosophy of ubuntu has core defining values such as caring, compassion, unity, tolerance, respect, closeness, generosity, genuineness, empathy, hospitality, conscience, conformity, sharing, and communitarianism. While the fundamental values of ubuntu form the basis or cornerstone of African ethics, they are also the foundational values found in many nations and cultures. The ubuntu philosophy can also provide the moral fabric that determines how nurses behave in Africa and around the globe.

Nursing and ubuntu are complementary. They both emphasize caring, which is the most important aspect of the nursing profession. In ubuntu, an individual is seen in terms of their ability to complement others. The emphasis of ubuntu is belonging to community: "I am because I belong." Just as a person can be born into an ubuntu-focused community, a nurse can be born into and nurtured in an ubuntu community where he/she can develop a sense of belonging, commitment, and compassionvirtues based on the communitarian principle of ubuntu. Communitarianism recognizes the importance of collectivism, solidarity, honest appreciation of another person, and sharing of opportunities, responsibilities, and challenges. The philosophy of ubuntu and its principles and values suggest a philosophical structure for the way in which senior and young nurses can work together in community (Poovan, du Toit, \& Engelbrecht, 2006). The ubuntu phi- losophy encompasses the welcoming spirit that can be the foundation for socialization of young nurses into the profession.

Care is an inborn characteristic that human beings possess. However, caring has in some ways become a "buzz word" used by people to describe such activities as caring for their skin, flowers, pets, and other material objects (Mulaudzi, Troskie, \& Mokoena, 2000). The care referred to in ubuntu philosophy is more like that of a mother and father caring for their child. Applied in nursing, senior nurses would implement caring, ubuntu philosophy by welcoming, nurturing, and affirming young nurses to the profession and striving to help them feel part of the nursing community. The values of ubuntu imparted from a senior to a young nurse are commensurate with the ethical code of nursing that identifies the importance of nursing care, which addresses the unique needs of each patient (International Council of Nurses, 2006). The patient is the center of the relationship. Although the nurse using ubuntu philosophy recognizes the individual need of each patient, persons must also be viewed as part of a community. Each nurse and patient is complementary with others in the community. This strong sense of "self-in-relation" within community is foundational to holistic nursing (Hall \& Allan, 1994). It is also fundamental to reconciliation, which is one of the goals of conflict management and consensus building suggested by ubuntu philosophy (Mulaudzi, 2007). These community-building values are achieved through teamwork: a concept well-known by nurses.

\section{Collectivism and Solidarity}

In ubuntu, teamwork falls under the principle of collectivism and solidarity. There is a belief that "munwe muthihi a u tusi math$u t h u$ " (one finger is not able to pick up more grains of rice from a bowl). This African idiom can be applied metaphorically to nursing: one nurse alone, whether young or senior is not able to fulfil or achieve the goal or vision of the profession. Teamwork, 
as emphasized in ubuntu, has been shown to have an impact on the efficiency, productivity, and growth of the profession (Poovan et al., 2006). In ubuntu philosophy, one nurse's decision affects all nurses. Although the issues of seniority and leadership positions in nursing remain, the spirit of togetherness prevails.

Nurses who embrace ubuntu are obliged to assist others because they understand that "they are what they are" because of others. Nurses "are what they are" also because of their patients. This spirit of teamwork or collectivism can uplift all patients and nurses and make life easier for everyone involved. Some of the language used in ubuntu-focused collective decision-making includes such terms as " $d z$ unde" (working together). Dzunde may be applied in nursing in a variety of ways, such as in team nursing in hospital wards, community engagement, teamwork when conducting research, and writing grants or other publications. Nurses who work on ubuntubased teams welcome each other so that when new nurses join the team or community, they know and feel that their additional "fingers" have added to the "hand" that assists the community in carrying its responsibilities.

The goal of ubuntu is to ensure a happy, quality human life (Broodryk, 2002). When one has been socialized within a culture that emphasizes collectivism it is difficult for that one to be self-centered. Collectivism and the sense of belonging can become part of one's personal traits, which are not easy to unlearn (Poovan et al., 2006).

Collectivism and solidarity promote cohesiveness. They encourage a depth of sharing that inspires strong team collaboration. In the spirit of ubuntu, nurses from different countries may be better able to work together and share knowledge without fear, show mutual affection and love for one another, and better able to promote the global vision and goals of care which are at the heart of the nursing profession.

\section{Communitarianism}

The concept of communitarianism, a part of ubuntu philosophy, relates to the sense of belonging (Burnett, 2006) and being a part of the community. It is applicable to nursing. The feeling of being a nurse and belonging to a group of professionals with a common vision can foster self-fulfilment in the individual nurse (Lekhuleni, van der Wal, \& Ehlers, 2004). However, as young nurses join the profession they must be welcomed to that nursing community to ensure that they begin to develop the sense of belonging that is so important at that time of transition. New nurses need one or more members of the community to be with them so that they can learn the ways of the community. Communitarianism provides new nurses the opportunity for engagement and interconnectedness, which fosters the spirit of caring within and among members of the professional nursing community. In African Zulu language there is a phrase, "simunye," which means "we are one." This phrase emphasizes the spirit of togetherness and of the obligation nurses have to trust one another and to develop open communication. Senior nurses in the spirit of simunye, who model this trust, invite and welcome young nurses to do the same. They are the leaders in the community-building process.

\section{Participatory Decision-Making and Leadership}

Leadership styles based on ubuntu emphasize the promotion of unity, shared vision, and inclusiveness. The ubuntu leader engages all levels of nurses, young to senior, in decision-making. Their input is respected and valued. The respect in ubuntu is not one sided. There is reciprocity between young and senior nurses. In an African context, age plays a very important part in community and is associated with wisdom. Power in relationships is based on respect. A young nurse respects a senior nurse; but, in the ubuntu tradition, a nurse who is senior in terms of education or hierarchy must also respect those who are younger. Reciprocity makes it easier for both leaders and followers to feel at home

(Mapadimeng, 2007).

The ubuntu philosophy emphasizes affirmation and nurturing of each nurse's contribution. The leader's responsibility is to acknowledge community or team members and to help them feel appreciated. This is emphasized by an idiom, "vhathu ndi mapfula vha a dolwa" (Tshivenda language). The literal translation of this is "people are like body lotion - they are applied." When one applies body lotion the skin is nurtured and nourished so that the skin is smooth. The purpose of the lotion is to avoid skin damage and cracks. Similarly, if a person does not belong because he/she is not surrounded and supported by others (the lotion), the person will crack like unnourished skin. The actual meaning of the Tshivenda phrase is similar to the English idiom, "No man is an island." In the ubuntu relationship, mentors are obliged to nurture and affirm their young. They must find that real sense or spirit of motherhood, fatherhood, sisterhood, and brotherhood within themselves so that they can share it with others. Senior nurses, who lead with a shared vision of nursing, are the "lotion" for young nurses with a community connection that instils pride in their choice to become a professional nurse.

\section{Sharing Opportunities, Responsibilities, and Challenges}

Another important principle of ubuntu is the sharing of community opportunities, challenges, and responsibilities (Broodryk, 2002). This sharing principle emphasizes acknowledgement of each community member's contribution, qualities, and gifts. Honest appreciation has been shown in research to open the heart and allow people to share their skills and knowledge (Institute of HeartMath, 2008). An individual with ubuntu does not base decisions on individual gain but on what can be gained for the upliftment of the community (Mulaudzi, 2007). Those who are knowledgeable share their expertise with others. Experienced nurses who embrace ubuntu possess an integrity and selflessness that causes them to 
make decisions that are in the best interest of the nursing profession. Ubuntu philosophy guides nurses to look beyond financial gain and other material benefits. They can possess integrity and openness about all decisions and actions that they make. There is a belief that if nurses share their knowledge, their skills, and their being with patients and colleagues that they will receive the prosperity and abundance that follows the act of sharing. This phenomenon is congruent with the caring ethic of nursing in which nurses are to possess qualities such as compassion and empathy (Mulaudzi, Troskie, \& Mokoena, 2000). When senior nurses engage in sharing, they model empathy for young nurses.

Nurses experiencing connection, consensus, unity, and deep respect in their professional communities realize that ubuntu is present. All of the concepts upon which ubuntu philosophy is constructed serve a purpose: to instil an open, spiritual intention in oneself and others, which can lead to greater peace and harmony. When nurses nurture their own with philosophies such as African ubuntu, the intention is not only that the philosophy will be integrated into one's personal practice but that the thoughts and beliefs will become an active part of nursing's professional culture.

\section{Weaving Cultural Tapestry}

When students enter nursing programs, they carry their culture of origin with them. While they are in nursing school they learn about professional nursing culture from their faculty. Cultural connections and clashes can occur within a student as a natural result of changes associated with entering nursing culture. Gradually, through the socialization process of connecting with practicing nurses, nursing faculty, and scholars, students absorb what they perceive to be the archetypal representation of nursing culture with its associated beliefs, norms, and ways of being. During this sensitive period of student acculturation, behavior that is uncivil and does not express a welcoming attitude of ubuntu may be mis- construed and even internalized by the student nurse as the defining typical demeanor of professional nurses.

Professional acculturation is a complex process. Teaching core professional values is important as a means to creating a shared professional language (Shaw \& Degazon, 2008); but the acculturation process does not stop with values identification. In nursing, professional values are demonstrated within the context of the nurse-patient relationship. Just as each new nurse must find his/her own manner of comforting a patient, based upon caring principles, they must also weave their own cultural thread into the greater "tapestry" of the professional culture that supports and defines their practice in society. They must find a way to integrate the values, beliefs, and practices related to health, life, and ways of being learned from their parents and cultures of origin with those of the existing professional nursing culture.

Culture is a dynamic social construction, and in nursing culture changes or shifts can occur as each new nurse enters the profession, first in nursing school and then again as they start their first nursing position. Senior nurses who are enthusiastic about the possibilities of change may be more welcoming of young nurses and less resistant to having young nurses share their personal cultures, the thread that they bring to the professional tapestry. But those who prefer to maintain the status quo can be less inclined to interact with young nurses and may actually suppress the ideas, values, beliefs, and practices of young nurses. This cultural suppression is part of the scenario identified as "eating the young" before a change can occur that will cause the professional environment and culture to accommodate the addition of a new person.

Other senior nurses are not threatened by the changes that young nurses represent. They openly welcome the ideas that the young nurses bring. In ubuntu, senior nurses diplomatically include nursing students and young graduate nurses in searching for solutions to professional problems.
Research has shown that young nurses can be highly intuitive (Ruth-Sahd \& Hendy, 2005) and therefore may have an astute sense of new solutions to old problems. By inviting young nurses to share their creativity and ingenuity, seniors grow the community and have a hand in the forming of young nurses' professional identities.

The community provides a scaffold for solving the tough social problems nurses face today. Adopting community-building philosophies, such as ubuntu, may promote greater awareness of the needs of young nurses, as well as senior nurses who would support their entry into the profession. Cultural diplomacy is one way to demonstrate the awareness gained through utilization of ubuntu, community-building philosophy.

\section{Demonstrating Cultural Diplomacy}

For the last 2 decades, the concepts of cultural competence, cultural sensitivity, and trans-cultural nursing have been explored extensively as they relate to nursing practice and education. Educational experiences in cultural sensitivity and transcultural awareness inspire in students and practicing nurses a greater knowledge of and compassion for cultural differences. Cultural diplomacy is the action one takes in the process of seeking cultural competence; it is also an expression and demonstration of the internalized qualities of cultural awareness and sensitivity. The central skills of cultural diplomacy are tactful communication and negotiation.

Diplomacy is a highly refined communication skill used with the intention of developing and maintaining relationships between different cultures. It is a potential antidote to the culture clashes that can occur in relationships, such as those between teacher and student and between young and senior nurses. Culture clash occurs when people with different perspectives seek to extend their influence by convincing others of the "rightness" of their views. Culture clash is the greatest obstacle to community building. At the center of culture clash is the 
fear of loss of control and the subsequent need to dominate others and convert them to one's own cultural beliefs and practices. Senior nurses eating their young may be the result of attempts to culturally dominate and convert.

American author and psychologist $\mathrm{M}$. Scott Peck (1987) wrote that the purpose of community building is peace making. He also proposed that as long as people try to "convert and heal" others and attempt to turn them toward their own paradigm of the world, true community and therefore peace are not possible (Peck, p. 68). The diplomat or peace maker, as Peck suggested, does not seek to convert and heal; he/she uses the skill of tactful negotiation to establish and maintain open communication without arousing hostility between parties. The diplomat's purpose is to keep dialogue open so that solutions to problems that satisfy all involved parties can be found.

Senior nurses who want to welcome the young nurse are often engaged, consciously or unconsciously, in a process of negotiating the integration of the young nurse's culture with the existing structures of the professional nursing culture. It is not welcoming to a young nurse to ignore their enthusiasm and desire to contribute and then demand that they conform in all ways to the dominant culture, i.e., the status quo. It is also unreasonable, and perhaps harmful, to expect that senior nurses will forfeit any of the status quo or cultural balance that they may have achieved through years of hard work and community building. Cultural diplomacy suggests a middle ground; a way of interacting that is, as in ubuntu, open and inclusive. The senior nurse acting as cultural diplomat on behalf of the profession shares the history and culture just as parents share creation stories with their children. Yet at the same time the senior nurse recognizes that the young nurse is not a child but a talented person with many ideas. Young nurses bring their ideas and enthusiasm for nursing as a gift to share with the greater nursing community if only they can find a colleague willing and able to listen to, re- ceive, and affirm them with consensusseeking dialogue in the spirit of ubuntu.

Cultural diplomats promote community building. They honor their own and another person's culture: the beliefs, values, and way of knowing the world and of being in it that they have brought to the profession. While the term diplomacy is more commonly applied to international and political relationships, cultural diplomacy is not unknown in the international community. All relations between peoples are cultural in nature. Nursing and the nurse-patient relationship are also cultural constructions. Cultural diplomacy promotes the free exchange of ideas among peoples. The foundation for cultural diplomacy is education and example (Feigenbaum, 2001). As it is applied to nursing and healthcare, cultural diplomacy suggests the actual acknowledgment of the diversity of health beliefs and practices encountered within nursing as a professional culture, as well as among individual nurses and patients.

The purpose of cultural diplomacy is to improve communication and understanding. Its goal is to build long-term relationships within the profession and with patients, which can lead to an increasingly peaceful global community that is open to sharing all health beliefs, practices, and systems. It is senior nurses, positioned to mentor young nurses, who have the best opportunities to engage in diplomatic exchanges, community building, and culture sharing.

\section{Mentoring Young Nurses}

Mentoring enables the smooth transition from novice nurse to a knowledgeable practitioner who is self-reflective and self-confident, and able to negotiate professional and patient relationships well (Santucci, 2004, pp. 275, 278). A mentor is expected to enable the mentee to navigate the work environment, to offer vision, to encourage, to develop trust, to care, and to provide protection. Inherent in ubuntu philosophy is the notion of mentoring and building the capacity of nurses to create community. The principle of "I am because you are" makes it possible for people to be with each other and for each other and to value each other. Young nurses entering the profession need to be supported, nurtured, and guided by mentors. African philosophy suggests that without ubuntu one lacks an indispensable ingredient to being human and that the person who has ubuntu is known to be one who is compassionate and gentle and who will not take advantage of others (Haegert, 2000). Mentors in nursing who integrate ubuntu philosophy reflect these human qualities during the process of guiding and socializing nurses. Mentoring was defined by Dorsey and Baker (2004) as a "planned pairing of a more experienced person with a lesser skilled individual for the purpose of achieving mutually agreed upon outcomes" (p. 260). They asserted that during the mentoring process, the mentor and mentee experience caring: a core ideal of ubuntu philosophy.

The role of mentoring is to facilitate the growth of young nurses, both educationally and personally. Mentors, who are like the "fertilizer" used in a garden, nurture and cultivate the young nurse who is like a "seed." The mentor creates the soil or environment in which the mentee can thrive. Diverse African cultures believe that people are like the soil that needs to be fertilized to enable seeds to grow and thrive well. The mentee needs the mentor, the fertilizer, to be able to feel that they are a part of the community of nurse-carers so that they can be better able to render quality care. As the mentor and mentee build trust they also build a spirit of commitment to nurse others. Mentors support young nurses by instilling accountability and responsibility (Lekhuleni et al., 2004). The mentor-mentee team is a primary relationship that encourages and empowers each young nurse to acquire more skills and contribute with their whole heart to the global nursing mission of caring.

Mentors provide the educational setting for the development of the mentee's capacity to experience caring through memories, feelings, past experiences, and existential 
moments. Mentors are diplomatic and protective of the vulnerable young nurses whom they are guiding toward professional life (Haegert, 2000). Mentors accomplish acculturation and socialization by teaching, coaching, sponsoring, protecting, and providing challenging work assignments (Dorsey \& Baker, 2004). As mentees are guided by their mentors, they gain confidence in the skills necessary to assume the role of a professional nurse. With the assistance of the mentor, young nurses are able to find their way to independent practice after the mentoring process ends.

Mentoring provides "effective and systematic support for nurses, facilitates their professional development, and enhances coordination of care within the context of general practice" (Gibson \& Heartfield, 2005, p. 50). Socialization of students involves empowering them with skills relevant to the demands of the profession. Professionalism requires that each young nurse learn the culture of the profession. By learning the culture of a profession, young nurses acquire the values, attitudes, and practices that make a profession distinct (Gray \& Smith, 1999). The mentoring-learning environment for young nurses must be open so that they can feel safe to explore and develop their abilities (Yoder-Wise, 2007). Mentors must nurture and affirm the young nurse's potential to add to established professional culture.

According to ubuntu, when a person is nurtured and affirmed they are able to grow holistically: spiritually, emotionally, mentally, and physically. The presence of the mentor, according to Phillips et al. (as cited in Nettleton \& Bray, 2008), is crucial to young nurses' well-being and potential for learning. Additionally, studies suggest that mentors also benefit greatly from the mentoring role especially when mentoring is a formally recognized activity. A mentor's professional development is enhanced through interactions with mentees. Mentors help mentees overcome difficulties, discuss problems, and fulfil professional goals. They are the mentee's diplomatic entrée into a welcoming professional community.

\section{A Case Study}

Nelisa is a registered operating room (OR) nurse from South Africa who has been hired by Hospital A in the United States. When she arrives, she is welcomed by the nurse recruiter and given the usual orientation given to new employees. She is shown the way in which to use the equipment, of which she is not accustomed to and the routine followed in the surgical units.

However, by virtue of the fact that she is from a different cultural background, she started feeling uneasy and stressed about nurse-to-nurse communication. She was assigned a mentor named Jennifer in whom she confided her feelings. Nelisa told Jennifer that she was concerned about acceptance as a foreign employee, that she was worried about her family in South Africa, and that she was feeling lonely. Jennifer, using ubuntu philosophy, invited Nelisa for tea and a discussion about her orientation program. During her discussion with Nelisa, Jennifer began to realize that although culture was discussed in the hospital orientation in terms of patient care, new nurses such as Nelisa were perhaps not receiving the sociocultural support they needed to adapt to the professional culture of Hospital A and its OR. Jennifer asked Nelisa about this. Nelisa said that she would have liked to have learned more about the culture, values, beliefs norms, and traditions of the American nurses with whom she was now working. They agreed that the ward needed an opportunity for nurses to share African and American nursing culture in a relaxed environment. Nelisa was happy with her mentor's response. She felt that that by being asked her opinions she was being valued and respected. Jennifer, acting as cultural diplomat between her African and American staff members, told Nelisa that she would arrange for the event. Nelisa told Jennifer that she appreciated her help. Jennifer observed that Nelisa's body language expressed greater ease. She arranged for a cultural event to promote nurse-to- nurse caring. Jennifer arranged for pizza to be delivered to the event and for Nelisa's favorite South African food, Braai (barbequed lamb and chicken), to be prepared by the hospital cafeteria for everyone to taste. She also invited two South African nurses from other wards to meet Nelisa and to help her teach a traditional codesa dance to the OR nurses. She arranged for another colleague to teach American line dance to everyone. The event and the discussion that ensued enhanced the cultural awareness of the mentor, mentee, and nurse colleagues. In the process, Nelisa, Jennifer and their nurse colleagues realized that they all possessed and demonstrated some of the virtues of ubuntu philosophy: kindness, generosity, friendliness, modesty, helpfulness, humility, compassion, cohesiveness, and commitment. The event demonstrated the importance of putting the philosophies of ubuntu and cultural diplomacy into action in hospital mentoring programs where the goal is to create a welcoming community for nurses of all cultures.

\section{Conclusion}

Nurses are living in a fast-paced changing society that often emphasizes individualism. Independence, rather than caring for others may be rewarded, and competition, rather than community-building, often becomes the sociocultural norm. Ubuntu philosophy stresses the advantages of interdependence and community. Cultural diplomacy identifies the benefits of shared belief and ways of knowing the world. Mentoring recognizes the rewards of mutuality. Ubuntu, cultural diplomacy, and mentoring are process-oriented solutions to the problem that some senior nurses eat their young. All suggest the need for cultural changes as well as shifts in consciousness. Ubuntu, cultural diplomacy, and mentoring are a manifestation of nurse-to-nurse caring in action. All three help to guide the development of a nursing community that is receptive and affirming of young nurses' ideas and innovations and welcoming of their enthusiasm, inquisitiveness, culture, 
and creativity that is needed for the growth of the profession that they will very soon inherit.

\section{References}

Broodryk, J. (2002). Ubuntu: Life lessons from Africa. Pretoria, South Africa: National Library.

Burnett, C. (2006). Building ubuntu through community clubs. African Journal for Physical, Health Education, Recreation, and Dance, 12(2), 123-137.

Clark, C., \& Carnosso, J. (2008). Civility: A concept analysis. Journal of Theory Construction and Testing 12(1), 11-15.

Clark, C., \& Springer, P. (2007). Thoughts on incivility: Student and faculty perceptions of uncivil behavior in nursing education. Nursing Education Perspectives, 28(2), 93-97.

Dorsey, L., \& Baker, C. (2004). Mentoring undergraduate nursing students:

Assessing the state of the science. Nurse Educator, 29(6), 260-265.

Feigenbaum, H. (2001). Globalization and cultural diplomacy. Center for the Arts and Culture. Retrieved March 12, 2008, from http://www.cultural policy.org/ pdf/globalization.pdf

Gibson, T., \& Heartfield, M. (2005). Mentoring for nurses in general practice: An Australian study. Journal of Interprofessional Care, 19(1), 50-62.

Gray, M., \& Smith, L. (1999). The professional socialization of diploma of higher education in nursing students (project): A longitudinal qualitative study. Journal of Advanced Nursing, 29(3), 639-647.

Haegert, S. (2000). An African ethic for nursing? Nursing Ethics, 7(6), 492-501.

Hall, B., \& Allan, J. (1994). Self in relation: A prolegomenon for holistic nursing.
Nursing Outlook, 42(3), 110-116.

Institute of HeartMath. (2008). Science of the heart: Exploring the role of the heart in human performance. Retrieved September 16, 2008, from http://www. heartmath.org/research/science-of-theheart.html

International Council of Nurses. (2006).

The ICN code of ethics. Retrieved

September 16, 2008, from

http://www.icn.ch/icncode.pdf

Kamwangamalu, N., \& Nkonko, M. (1999). Ubuntu in South Africa: A sociolinguistic perspective to a pan-African concept. Critical Arts Journal, 13(2), 24-42.

Kehoe, J. (2007). Ubuntu. Retrieved September 10, 2008, from www.learnmindpower.com/articles/ubuntu/html

Lekhuleni, E., van der Wal, D., \& Ehlers, V. (2004). Perceptions regarding the clinical accompaniment of student nurses in the Limpopo province. Health $S A$ Gesondheid, 9(3), 15-27.

Libster, M., \& McNeil, B. (in press). Enlightened charity: The holistic nursing, education, and "advices concerning the sick” of Sister Matilda Coskery, 1799. 1870. Golden Apple Publications.

Mapadimeng, M. (2007). Ubuntu/botho, the work-place and "two economies." Africanus, 37(2), 257-271.

Mulaudzi, F.M. (2007). Comments on the XIV International HIV/AIDS Conference: An "ubuntu” perspective on religion and theology, 2(14), 105-115.

Mulaudzi, F., Troskie, R., \& Mokoena, J. (2000). Basic ethics in nursing. Sandown, South Africa: Heinemann.

Nettleton, P., \& Bray, L. (2008). Current mentorship schemes might be doing our student a disservice. Nurse Education in Practice, 8(3), 205-212.
Peck, M. (1987). The different drum: Community making and peace. New York: Touchstone.

Poovan, N., du Toit, M., \& Engelbrecht, A. (2006). The effect of the social values of ubuntu on team effectiveness. South African Journal of Business Management, 37(3), 17-27.

Santucci, J. (2004). Facilitating the transition into nursing practice. Journal for Nurses in Staff Development, 20(6), 274284.

Shaw, H., \& Degazon, C. (2008). Integrating the core professional values of nursing: A profession, not just a career. Journal of Cultural Diversity, 15(1), 4450.

Sullivan, L., (Ed.). (1991). Louise De Marillac spiritual writings: Correspondence and thoughts $(\mathrm{L}$. Sullivan, Trans.). New York: New City Press.

Rieck, S., \& Crouch, L. (2007). Connectiveness and civility in online learning. Nurse Education in Practice, 7(6), 425-432.

Ruth-Sahd, L., \& Hendy, H. (2005). Predictors of novice nurses' use of intuition to guide patient care decisions Journal of Nursing Education, 44(10), 450-458.

Webb, C., \& Shakespeare, P. (2008). Judgments about mentoring relationships in nurse education. Nurse Education Today, 28(5), 563-571.

Yoder-Wise, P. (2007). Leading and managing in nursing (4th ed.). St. Louis, MO: Mosby.

\section{Author Note}

Fhumulani Mavis Mulaudzi, Associate Professor Research, School of Nursing Sciences, Northwest University, Potchefstroom, South Africa. Martha M. Libster, Associate Professor of Nursing, College of Nursing, East Carolina University, Greenville, North Carolina. Salaminah Phiri, Department of Nursing Science, University of Pretoria, Pretoria, South Africa.

Correspondence concerning this article should be addressed to Fhumulani Mavis Mulaudzi, Associate Professor Research, School of Nursing Sciences, Northwest University, Private Bag 6001, Potchefstroom Campus, Potchefstroom, South Africa 2520. Electronic mail may be sent via Internet to mavis.mulaudzi@nwu.ac.za 
Copyright of International Journal for Human Caring is the property of International Association for Human Caring and its content may not be copied or emailed to multiple sites or posted to a listserv without the copyright holder's express written permission. However, users may print, download, or email articles for individual use. 